\title{
Teacher Education through Art: How to Teach Social Sciences through Artwork -The Student-Teachers' Views
}

\author{
Dr. Vasiliki Brinia \\ Teacher Education Program \\ Athens University of Economics and Business \\ Dr. Reni Giannimara \\ Athens School of Fine Arts \\ Paraskevi Psoni \\ Teacher Education Program \\ Athens University of Economics and Business
}

George Stamatakis

Athens School of Fine Arts

Received: February 6, 2018

Accepted: March 13, 2018

Published: March 20, 2018

doi:10.5296/gjes.v4i1.12607

URL: https://doi.org/10.5296/gjes.v4i1.12607

\begin{abstract}
The present paper aims at presenting an innovative approach to educating teacher-candidates through the art. More specifically, it aims at exploring the benefits of this approach for student-teachers and for their future teaching of social science subjects. It is an experiential approach, based on a multi-level methodology, developed and implemented through the collaboration of the Teacher Education Program of Athens University of Economics and Business with the Aalto University and the Athens School of Fine Arts. After the completion of the implementation of the specific teaching method, the student-teachers have been interviewed, in order to detect their views on the effectiveness of this method, which has been
\end{abstract}




\section{Macrothink

introduced for the first time in the Teacher Education field in Greece. The results are positive with the interviewees reporting having achieved an in-depth and multi-perspective understanding of the matter in discussion as well as enhanced collaborative skills among other benefits.

Keywords: Experiential learning, Arts in teaching, Social sciences, Transformational learning, Teacher education program, Interdisciplinary approach 


\section{Introduction}

Over the last years, there has been a discussion about the renewal of the educational system that has been fortified in its four main towers: language, mathematics, history and science. The current challenge is to find ways to make school attractive to students and help the learner "learn how to learn", especially nowadays when education is being treated as part of the production process, increasing competitiveness among students. In this context, art in school is considered as a waste of time. Education through art could contribute to the development of a well-rounded personality, which is an indispensable trait for a teacher and one of the purposes of education in general. In this respect, the present field-research contributes to the development of an innovative and first of its kind comprehensive methodology for the use of artwork in teaching social sciences to teacher-candidates, who will be, after the completion of this process, knowledgeable enough and able to utilize in the future this method in their high-school classes.

The methodology has been developed through the collaboration of the Teacher Education Program of the Athens University of Economics and Business (TEP AUEB) with the Athens School of Fine Arts and the Aalto University of Helsinki in Finland. The lesson chosen to be taught through the art derives from the subject of "Political Education" of the first grade of senior high-school and it is about Economic Migration. At the end of the implementation of the methodology of teaching through the art, the student-teachers created, through teamwork, artworks that varied to a great extent. The artworks included, among others, installations and even a short film including a song written, composed and performed by the student-teachers, who had been inspired by the topic of Economic Migration. The student-teachers' views have been detected through semi-structured interviews, in order to evaluate the effectiveness of the methodology introduced.

\section{Literature Review}

As early as the 1970s, Paulo Freire had written about the narrative nature of teaching, inspired by the situation in Latin America and, more specifically, in Brazil, but without limiting the value of his findings to a single country or continent. In particular, Freire (1970) reported that a teacher often speaks to students about reality as being static, stationary and predictable, and, even more, without linking it to students' personal experiences. Teachers' purpose is often to cover all the material, cut off from everyday life through which it has originally been created. Art in teaching, on the other hand, serves exactly the opposite purpose: it connects the syllabus with students' reality and takes a tangible form in their minds.

Similarly, Dewey had already pointed out since 1930 that art should not be viewed as an educational "luxury" or treated with a superficial approach in school, but should, instead, be treated as a factor of paramount importance in cultivating critical thinking and refining students' personalities, a fact that should always be a priority in the educational and pedagogical practice, according to Dewey. In particular, regarding the refinement of students' personalities through works of art, this is achieved when students are emotionally activated through an artwork, and in doing so, they get to appreciate it deeper. According to Dewey, 
students learn, in this way, to appreciate things, in general and, thus, refine their personalities. Finally, Dewey criticized the schools that overlooked and sacrificed the needs and feelings of students in the name of an impersonal lesson. (Nakamura, 2009; Smith, 1971).

At this point, it is important to mention that neuroscientists claim that through the stimulation of the person's emotions, "Amygdala" is activated, the part of the brain responsible for both controlling emotions and constructivist memorization, and therefore, responsible for learning and memory. (Sharpe \& Schoenbaum, 2016) Therefore, emotions stimulated through art contribute to better memorization of the material of the lesson by students.

David Perkins put great emphasis on the value of art in teaching, through his book "The Intelligent Eye: Learning to Think Looking at Art," which he published in 1994, thus inaugurating a new era in which art would obtain an influential role in education. The so-called "Perkins' nine points" embodies the basic principles of his thinking. The first chapter of his book refers to the intelligence cultivated through art. This refers to the fact that man learns to think in the right way by observing something and not as a passive receiver. Through artwork, people observe, are invited to reflect on and draw conclusions about its importance.

Perkins' second point (1994) refers to the fact that intelligence is not confined to the Intelligence Quotient (IQ) but is rather expressed under three basic forms: neurological intelligence, empirical intelligence, and reflective intelligence. He argues that all three are equally important, however, it is not good to neglect the reflective intelligence that can be cultivated through art and can help the functionality of the two other forms of intelligence.

In the third chapter and chapter of his work, Perkins (1994) argues that, through the art, people realize that they are not able to know everything with certainty about a certain matter and that their personal interpretations are simply their personal, subjective and limited perspectives on the subject. In other words, by observing an artwork, people realize that the "invisible" elements of the artwork are subject to multiple interpretations and not to a single and absolute one.

The fourth point refers to the "cognitive gaps" and the "traps of intelligence" of people. The "cognitive gaps" refer to actions we do without having the necessary background knowledge. For example, when we observe an artwork, we may come to the wrong conclusions about it, because we may have previously not studied the artist's or the work's history. This event can also be generalized in situations where we draw conclusions about situations or people without knowing their history. "Intelligence traps" refer to the rush of people to draw conclusions because of their empirical intelligence, without having devoted the appropriate time to think in more detail on the subject, often resulting in false conclusions. (Perkins, 1994)

According to Perkins' fifth point (1994), a great danger is the impressiveness of the audience, which he calls "Impressionism", separating it from the well-known French art movement. In other words, people make two essential mistakes when they are not familiar with art: first, after a simple look at the artworks, they feel content for having understood them, and 
secondly, they grasp them as "good", "moderate" or "bad" at once and fail to understand them in depth.

The sixth point is about the fact that art helps people think in a broader and more adventurous way and not only through the most obvious way. The way to achieve this is to continually investigate things and to avoid supporting opinions solely based on one's empirical intelligence. Perkins' seventh point (1994) suggests that, in order for people to cultivate a clearer and deeper look for things, they should work on it and control their reflective intelligence. Perkins' eighth point refers to the need to organize the above points so that people's organizational gaze on things arises. This proposed "orchestration of the look" requires time and systematic effort.

One way to achieve this orchestration is the "critical review" method of Edmund Burke Feldman's four-stage process. The first step is the "description", the mere reference to what the public observes, without any criticism. The second stage is the "formal analysis", which includes, according to Feldman, the logic of the organization of the data, in order to interpret their existence. Direct and clear conclusions should be avoided at this point. In the third stage, the "interpretation" of the project seeks to understand the possible messages that the artist tries to convey to the audience through his work. Feldman's fourth and final stage invites the public to "critique" the quality of the project. This criticism should not be based on the personal preferences of the public but on the quality of the aesthetics of the artwork when compared with other artworks that are reminiscent of the same subject. (Perkins, 1994).

Finally, in his ninth point, Perkins (1994) underlines the most obvious of his previous analysis: the need to combine empirical intelligence that leads to hasty conclusions with reflective intelligence leading to wider, deeper and more accurate conclusions.

In the case of teaching in the field of teacher education, but also in teaching social sciences in senior high schools, art constitutes a form of experiential learning of the material to be taught. At this point, the experiential learning theory (ELT) needs to be explained. ELT refers to the knowledge generated by the learner through the transformative function of experiences. This is achieved through the transformation of a concrete experience into the abstract conceptualization of a topic with the help of reflection. (Kolb, 1984).

One of the few recent studies on the teaching methods utilized in social sciences subjects refers to the fact that multi-disciplinary and multi-theoretical research should be developed in teacher education, since this practice will motivate the future teachers to adopt such professional activities in their teaching. (Deem \& Lucas, 2006) Oreck (2004) very aptly observes that the majority of art-based teacher education programs do not aim at making teachers art specialist but rather at familiarizing teachers with art as an effective method of teaching, that enhances critical thinking and learning (Argyriou et al., 2016a, 2016b; Brinia, 2015; Brinia et al., 2015). However, the pressures deriving from the need to cover the material of the curriculum hinder the use of artworks in teaching. Teachers not being appropriately trained on how to use art in teaching or not considering it a serious teaching method might also be an important impediment in practice. (Amabile, 1996; Baum, Owen, \& Oreck, 1997; Gordon, 1999). 
3. Teacher Education through Art: The Collaboration of the TEP AUEB, the Athens School of Fine Arts and the Aalto University

\subsection{Methodology}

The methodology of this study followed an innovative multi-level approach. In the first phase, Aalto University undertook the teaching of a four-hour preparatory course in order to help teacher-students to get acquainted with some first artworks, that can be utilized in teaching social sciences, and the way teachers should approach them.

In the second phase, the Athens School of Fine Arts (ASFA) undertook the artistic exploration and the identification of the research questions. The next step was to form teams, each of which would create an artwork. After this step, an action plan was made and a timetable to follow was set. The keeping of a calendar was accompanied by regular feedback on the part of the Professors-responsible of the ASFA.

The third phase included the conception of the idea of a visual work by each group, its theoretical approach, the identification of the research sub-questions, as well as the organization of the required actions of internal organization of each group and the allocation of roles.

The fourth phase was about the collection of data by the teams, so as to be able to answer the research questions.

The fifth phase included the actions undertaken by the teams, so as to process the collected data.

The sixth phase regarded the reflective review of the data, both at an individual level and at team level.

The seventh phase was about the design and implementation of the idea as an artistic creation.

The eighth phase included the collaboration with a curator. At this phase, the artworks of the teams were presented to the public through an open exhibition.

The ninth and final phase included self-evaluation actions at individual level and at team level. These included a critical discussion among the members of each team, an open discussion in class, the writing of a final reflective journal and individual semi-structured interviews with the researchers.

Thus, experiential learning and qualitative research is the tool utilized for the present study. Semi-structured interviews are considered by many as the most appropriate tool for in-depth analysis of social phenomena in social science research. Besides, the semi-structured nature of the interview allows the researcher to customize the flow of the discussion according to the answers of each interviewee. (Qu \& Dumai, 2011) Therefore, further elaboration on each topic is achieved and the feelings and ideas of each interviewee get detected in an easier way. (Hammersley, 2007). 


\subsection{Population Sample}

The population sample of the study has been a convenient sample. 58 student-teachers of the TEP AUEB created artworks in their teams and after the end of the process they were interviewed. The sample consists of 11 male and 47 female undergraduate students aged between 21 and 40 years old, all of which were on their final year of undergraduate studies in AUEB.

\subsection{Findings}

On the question "What was your opinion on the usefulness of art in teaching before the creation of the artwork associated with economic migration?" almost all the interviewees answered that they had not connected the art with the teaching process in their mind before. P1 stated: "I didn't know that a connection could exist. I thought that there was no connection between the artistic expression and economic migration.". P11 stated: "In general, using art in the teaching process seemed a good idea, but I couldn't think that it could be associated with economic migration or with the context of social sciences in general.". P3 added: "I thought that art has certain value for education but I was not yet acquainted with its practical benefits.".

On the question of "How was your opinion about the usefulness of art in teaching changed after the creation of the artwork related to economic migration?" P3 answered that through the art she got deeply sensitized on the matter of economic migration. P4 underlined: "After the creation of the artwork, I realized through my team's artwork but also through the other teams' artworks the various and different ways of using art in education.". P32 mentioned: "Art in education may constitute a very useful tool for teachers if they manage to use it and connect it appropriately with the lesson.". P42 observed: "It seemed to me very useful, as I realized that students can approach and understand different aspects of the same phenomenon through the art.". P54 answered: "I realized that teaching through the art is one of the most important methods of experiential learning. Educators of different disciplines may collaborate, giving at the same time the opportunity to students to actively participate in the learning process and to acquire comprehensive knowledge on a single matter.". The vast majority of the interviewees answered -each one in a different way- that, after the creation of the artwork, they realized the value of art in teaching.

Regarding the third question "Do you think you understood the concept of economic migration better and deeper through your engagement with the work of art you created?", about two thirds of the interviewees answered that they understood the phenomenon in depth. P28 answered that, surely, through their own artwork and the other teams' artworks, they elaborated on the topic and studied all its aspects. P38 answered: "It helped me understand the problems, the thoughts and the feelings of those who immigrate. I got into their shoes.". P45 underlined: "Yes, because words are very poor to describe what an artwork can describe and it touches us much more.". P54 added that, through the artwork, they had the opportunity to approach the phenomenon in an experiential way and understand every aspect of it. However, the rest of the interviewees answered that they had already had a clear opinion on the phenomenon, even though, through the artwork, they had the opportunity to dedicate time 
to reflect on it.

On the forth question "Do you think it is useful to include art (artistic creation or art observation and analysis) in the field of education? Why? Would you adopt this teaching approach at your school as a teacher?", most of the interviewees answered in a positive way. P28 answered that she believes that art is of great importance in teaching for the essential understanding of different matters, but also for students' self-expression and agency of their own. She added that art in education also helps broaden students' intellectual horizons. P1 underlined that: "It is a useful combination as it escapes from usual practice and it stimulates the students' interest. Therefore, I would adopt it.". P4 mentioned: "Undoubtedly, art is useful in education. I would adopt it, since it constitutes a way of students' expressing themselves, it cultivates their critical thinking and their imagination as well as it improves their skills. It finally leads to the in-depth understanding of a topic.". P18 stated: "It is a very important combination because it generates a plethora of stimuli and it stimulates not only the cognitive function of the brain but also the emotional and the psychological. Of course, I am going to utilize this approach in my teaching.".

Regarding the question "What feelings did this experience give you?", P19 answered: "Initially, it generated a sense of stress and curiosity. Afterwards, a sense of suspense and, in the end, pride and contentment.". P22 mentioned: "It generated feelings of enthusiasm, joy and impatience. Later, it generated feelings of sadness and anger about the problem of economic migration that exists nowadays. Finally, it made me feel calm and deeply reflect on the topic of economic migration.". P21 added: "It made me feel a sense of responsibility towards the society and the problem of economic migration. It also made me feel joy for the artwork creation and for the collaboration with my colleagues.". P51 underlined that she fell stressed out but also happy, because she had the opportunity to discuss with economic immigrants, in order to complete the artwork. P55 mentioned joy, happiness, awe as well as understanding and compassion towards his fellow men. Most of the answers included the feelings cited above.

On the sixth question "Do you believe that the psycho-kinetic approach to the subject of economic migration through art (the stimulation of all human senses through the creation of a project) has helped to change your attitude/view of economic migration?", half of the answers were positive. P55 underlined that his attitude was changed because of the feelings that were generated during the creation of the artwork. Similarly, P31 answered: "I understood in-depth the immigrants' problems and I got into their shoes. Thus, I developed pro-immigrant feelings.". However, P21, for example, answered: "In general, I don't think that my views have been greatly changed, but I feel more that I have discovered an alternative way of expressing my views and feelings about the problem.". P30 added that there was no change in her view, because, through the artwork, her team wanted to express their already formed view on the problem.

On the seventh question "How did you experience the collaborative experience of creating an artwork?", the answers have been quite similar. P31 answered: "Despite the initial difficulties in terms of communication and coordination, I experienced a very good collaboration, which 
helped me improve as an individual. P19 stated: "The collaboration experience was, to me, the most positive aspect of the whole process, because I realized the great extent to which collaboration promotes and improves creativity.". P14 mentioned that not all her colleagues were interested in creating the artwork, but also that the "fermentation" of ideas led to a positive result that wouldn't be possible otherwise. P55 added that the members of his team cooperated effectively and that he learnt to work as part of a greater whole and as member of a team.

Regarding the question "Do you think that this teaching method can be used flexibly in any teaching unit or only in some thematic areas of your specialty? Why?", most of the interviewees answered that this method can be used in all units of a subject in social sciences. P10 mentioned: "I think that most units are suitable to utilize this method. Even in the case of units on which it's difficult to apply, I believe that, through appropriate search, the right artwork for the unit can be found.". P1 added that it can be used in all units, since art has no limits or restrictions. P30 similarly mentioned that it can be used in all units, since art is a way of expressing oneself regardless of the form it takes. P18 pointed out: "I believe it can be used in all cases, not with the same effectiveness though. Therefore, I find it should be utilized in a focused way, in specific lessons, so as to avoid saturation.".

Finally, on the question "If the process of the collaborative creation of the visual artwork had to be repeated, what would you change in the steps taken by your team or in the educational process as a whole?", the answers received varied. P5 pointed out that she would change the first step of the process, so as to choose the members of her team on her own. She thought that collaborating, with the persons she wants, would help her express herself in an easier way through the artwork. P18 answered that she would not change anything and that her team worked very effectively. P11 stated that she would prefer not to have started the creation of the artwork so early but rather to work for a shorter period more intensively. P4 answered: "Perhaps, I would change a bit the decision-making process of the team.". P46 answered: "I wish we had more time to accomplish the artwork.", and P50 added that she feels she needed a whole academic year to accomplish it adequately. However, there were also many interviewees that replied that they would not change anything in the process.

\section{Discussion of the Results}

The findings confirm the literature to a great extent and prove the effectiveness of the methodology. Most interviewees admitted that they had no idea on how to utilize artworks in their teaching and that after the completion of the methodology they realized the value of this technique in teaching. Through this answer, they remind of the fact that the appropriate teachers' training on how to use the art in their teaching is the key to the problem of the limited utilization. (Amabile, 1996; Baum, Owen, \& Oreck, 1997; Gordon, 1999).

Perkins' nine points are confirmed through the interviewees' answers, that report having developed a broadened way of thinking on the topic of economic migration after the creation of the artworks. Interviewees pointed out the limited individual view they had on the topic, which would not have changed without the critical discussion on the artwork, reminding, in this way, Perkins" "cognitive gaps" and "intelligence traps". (Perkins, 1994). 


\section{Al Macrothink}

Global Journal of Educational Studies ISSN 2377-3936 2018, Vol. 4, No. 1

Their answers on the third question confirm the value of the stimulation of the "amygdala" through the artworks (Sharpe \& Schoenbaum, 2016), since they underlined that they felt they were in those people's shoes, which helped them understand in-depth the reality of the phenomenon of economic migration.

Finally, the findings of the study provide a solution to Obeck's findings (2004), according to which teachers do not frequently use art in teaching because of the lack of appropriate training and lack of self-efficacy about using it. (Amabile, 1996; Baum, Owen, \& Oreck, 1997; Gordon, 1999).

\section{Limitations of Present Study and Suggestions for Future Research}

The present study has focused only on the use of art as a tool of teaching social sciences. Future researchers could also focus on other subjects that can be taught in secondary education through artwork. What is more, this field-research has been conducted for the first time this year, and, thus, has not yet had the opportunity to detect possible need for improvement in the process. In the future, researchers may repeat the study so as to include improvements in the methodology. For the same reason, as mentioned above, this study included only the views of student-teachers that graduated in 2017. Therefore, results of research of consecutive years are not available yet. Nevertheless, this fact does not hinder the recognition of the importance of the innovation of the present methodology and the positive findings that derive from student-teachers' feedback.

\section{Conclusion}

All in all, this study presented an innovative approach to teaching social sciences through art in an experiential way, that enables student-teachers not only to be involved in the learning process, but also to discover the material and the method on their own. Student-teachers' views have been very positive, proving that learning through the art is possible in almost all cases of material to be taught as well as it is a way of discovering a topic in-depth and see some of its aspects that they could not otherwise be seen without the collaborative creation and the review of the artwork inside the teams. Therefore, this methodology is seen as an experiential, interdisciplinary and collaborative approach that helps students develop their critical thinking, broaden their mind and enhance their understanding towards the various social phenomena and, thus, towards others.

\section{References}

Amabile, T. M. (1996). Creativity in context. Boulder, CO: Westview.

Argyriou, A., \& Brinia, V. (2016a). The contribution of arts in the intercultural education. Scholars Journal of Arts, Humanities and Social Sciences, 4(9B), 1052-1054.

Argyriou, A., \& Brinia, V. (2016b). European education policy and arts education, International Journal of Multidisciplinary Research and Development, 3(9), 200-202.

Barry, O. (2004). The artistic and professional development of teachers: A study of teachers' attitudes toward and use of the arts in teaching. Journal of Teacher Education, 55(1), 55-69. 
https://doi.org/10.1177/0022487103260072

Baum, S., Owen, S., \& Oreck, B. (1997). Transferring individual self-regulation processes from arts to academics. Arts Education Policy Review, 98(4), 32-39. https://doi.org/10.1080/10632913.1997.9936393

Brinia, V. (2015). The Art of Learning: Using artwork in teaching Economics. International Journal of Advanced Research, 3(9), 1500-1505. https://doi.org/10.9790/7388-0602018693

Brinia, V., Sokou, M., \& Stavrakouli, K. (2015). Teaching Economics in Secondary Education Through Modern Music: An innovative proposal. International Journal of Academic Research in Progressive Education and Development, 4(4), 31-43. https://doi.org/10.6007/IJARPED/v4-i4/1866

Deem, R., \& Lucas, L. (2006). Research and teaching cultures in two contrasting UK policy contexts: Academic life in Education Departments in five English and Scottish universities. Higher Education, 54(1), 115. https://doi.org/10.1007/s10734-006-9010-z

Freire, P. (2000). Pedagogy of the oppressed (30th anniversary ed.). New York: Continuum.

Gordon, E. W. (1999). Toward an equitable system of educational assessment. In E. W. Gordon (Ed.), Education and justice (pp. 119-136). New York: Teachers College Press.

Hammersley, M. (2007). The issue of quality in qualitative research. International Journal of Research and Method in Education, 30(3), 287-305. https://doi.org/10.1080/17437270701614782

Kolb, D. A. (1984). Experiential learning: Experience as the source of learning and development. New Jersey: Prentice-Hall.

Nakamura, K. (2009). The Significance of Dewey's Aesthetics in Art Education in the Age of Globalization. Educational Theory, 527-440. https://doi.org/10.1111/j.1741-5446.2009.00329.x

Perkins, D. N. (1994). The intelligent eye: Learning to think by looking at art. Santa Monica, CA: Getty Center for Education in the Arts.

Qu, S. Q., \& Dumai, J. (2011). The qualitative research interview. Qualitative Research in Accounting and Management, 8(3), 238-264. https://doi.org/10.1108/11766091111162070

Sharpe J. M., \& Schoenbaum G. (2016). Back to basics: Making predictions in the Orbitofrontal-Amygdala circuit, Neurobiology of Learning and Memory, 131, 201-206. https://doi.org/dx.doi.org/10.1016/j.nlm.2016.04.009.

Smith, C. M. (1971). The Aesthetics of John Dewey and Aesthetic Education. Educational Theory, 21(2), 131-145. https://doi.org/10.1111/j.1741-5446.1971.tb00502.x 


\section{Macrothink \\ Global Journal of Educational Studies \\ ISSN 2377-3936 \\ 2018, Vol. 4, No. 1}

\section{Appendix}

\section{The semi-structured interview questions}

1. What was your opinion on the usefulness of art in teaching before the creation of the art work associated with economic migration?

2. How was your opinion about the usefulness of art in teaching changed after the creation of the artwork related to economic migration?

3. Do you think you understood the concept of economic migration better and deeper through your engagement with the work of art you created?

4. Do you think it is useful to include art (artistic creation or art observation and analysis) in the field of education? Why? Would you adopt this teaching approach at your school as a teacher?

5. What feelings did this experience give you?

6. Do you believe that the psycho-kinetic approach to the subject of economic migration through art (the stimulation of all human senses through the creation of a project) has helped to change your attitude / view of economic migration?

7. How did you experience the collaborative experience of creating an artwork?

8. Do you think that this teaching method can be used flexibly in any teaching unit or only in some thematic areas of your specialty? Why?

9. If the process of collaborative creation of the visual artwork had to be repeated, what would you change in the steps taken by your team or in the educational process as a whole?

\section{Copyright Disclaimer}

Copyright for this article is retained by the author(s), with first publication rights granted to the journal.

This is an open-access article distributed under the terms and conditions of the Creative Commons Attribution license (http://creativecommons.org/licenses/by/3.0/). 